\title{
Needs of caregivers of children with cerebral palsy: A literature review
}

\author{
Rana Mohammed Diab Eloreidi ${ }^{1}$, Vahe Kehyayan*1, Frances Kalu ${ }^{1}$, Lisa Thornton ${ }^{2}$ \\ ${ }^{1}$ University of Calgary in Qatar, Doha, Qatar \\ ${ }^{2}$ Sidra Medicine, Doha, Qatar
}

Received: February 20, 2021

Accepted: April 24, 2021

Online Published: May 5, 2021

DOI: $10.5430 /$ jnep.v11n9p23

URL: https://doi.org/10.5430/jnep.v11n9p23

\begin{abstract}
Background and objective: Cerebral palsy (CP) is the most common motor disability that affects two to three children per 1000 worldwide. Caregivers are most often parents of children with $\mathrm{CP}(\mathrm{CCP})$ who are responsible for providing primary care. Caregivers of CCP face multiple challenges, such as the manifestation of the disease and difficulty in providing daily care. They also have psychological, social, financial, and informational needs. These needs may be met through participation in support groups. The objective of this paper is to identify the needs of caregivers of CCP and how participation in support groups may meet those needs.

Methods: A literature review was conducted to identify relevant articles on the needs of caregivers of CCP. Eleven articles published between 2008 and 2018 on caregivers' needs were retrieved and their quality was assessed using the Mixed Methods Appraisal Tool. The data collected were analyzed to identify key themes related to caregivers' needs.

Results: Four key themes of caregivers' needs were identified: informational, financial, social, and psychological. Support groups may help caregivers to meet their needs. As caregivers receive their needed support, they will able to improve their role in providing a high quality care for their children.

Conclusions: Caregivers of CCP have informational, financial, social, and psychological needs which may be met by membership in support groups. Support groups may potentially increase caregivers' knowledge, receive the needed support, decrease their level of stress, and improve their quality of life.
\end{abstract}

Key Words: Children with cerebral palsy, Caregivers, Support groups, Quality of life

\section{INTRODUCTION}

Cerebral palsy $(\mathrm{CP})$ is the most common motor disability that affects two to three children per 1000 worldwide. ${ }^{[1]}$ The World Health Organization (2011) reported that 95 million children worldwide have this disability while 13 million of these children have a severe form of the disability. ${ }^{[2]}$ Specific statistics on the prevalence of $\mathrm{CP}$ children in Qatar is not available because the statistics that is available captures all types of disabilities including CP. According to a report in
2017 by the Ministry of Development Planning and Statistics, the prevalence of individuals with disabilities in Qatar was $0.4 \%{ }^{[3]}$

Caregivers are most often parents of children with $\mathrm{CP}(\mathrm{CCP})$ who are responsible to provide primary care. Caregivers of $\mathrm{CCP}$ face different challenges, such as the manifestation of the disease, shortage in rehabilitation facilities, difficulty in scheduling hospital appointments, lack of attention to their needs, and difficulty in providing daily care. ${ }^{[4]}$ There are four

*Correspondence: Vahe Kehyayan; Email: vkehyaya@ucalgary.ca; Address: University of Calgary in Qatar, Doha, Qatar. 
common challenges that caregivers face when providing daily care: psychological, social, financial, and informational. ${ }^{[5]}$ They should be managed well in order to have positive improvements in their children's health conditions. Caregivers of CCP often have high levels of stress and depression. ${ }^{[6]}$ They need psychological, social, and emotional support to help decrease their level of stress and help them adjust and cope with their children's health condition. ${ }^{[4]}$ Caregivers often have a lack knowledge about CP; they need improvement in their knowledge about CP to empower them in providing the needed care for their children with confidence, and to improve the health condition and quality of life of their $\mathrm{CCP}^{[5]}$ It is vitally important to identify caregivers' needs to provide them with their needed support and use of community services. Therefore, the purpose of this literature review was to identify the needs of caregivers in caring for the CCP. This literature review was guided by the following research question: What are the needs of caregivers in the care of their $\mathrm{CCP}$ and how participation in support groups help some of those needs?

\subsection{Background}

Cerebral Palsy is a group of permanent disorders of movement and posture causing activity limitation that are due to non-progressive disturbances, which occur in the developing infant or fetal brain. ${ }^{[7]}$ It is often accompanied by disturbances in perception, cognition, sensation, behavior, communication, muscle and skeletal abnormalities, or seizure disorders. ${ }^{[8]}$ The needs of caregivers will be different between the three classifications. ${ }^{[5]}$ Children with CP with Gross Motor Function Classification System (GMFCS) levels I and II can move without assistance, do daily activities, and generally need fewer supports and interventions than more severe levels. However, children with CCP with GMFCS level III need an assistive device to achieve daily activities. While those with levels IV and V require a wheelchair for mobility and generally require assistance to achieve daily activities, and they are more likely to have secondary complications, such as hip disease, spine curve, and seizures. ${ }^{[5]}$

Cerebral Palsy occurs in neonates or early childhood because of trauma during or after delivery, which causes damage to brain cells. ${ }^{[1]}$ Damage in the brain also occurs from a defect in the normal development of the brain that often occurs before childbirth. ${ }^{[9]}$ There are many factors that can increase the chance for $\mathrm{CP}$ in infants and children. These factors include genetic problems, traumatic head injury, hypoxia, infections, severe jaundice, and maternal infections. ${ }^{[10]}$

The signs and symptoms of CP may appear in the first year of life when children are learning gross motor skills. ${ }^{[9]}$ The main features that are often seen in $\mathrm{CP}$ are movement prob- lems, learning difficulties, and communication and behavior problems. The impaired movement in CCP can be associated with involuntary movement, floppiness, rigidity of trunk and limbs, stiffness of muscles, abnormal reflexes, and abnormal posture. They may have limited movement on one side of the body or the whole body and excessive drooling, swallowing and speech problems, seizures, hearing and vision impairments, and urinary incontinence. ${ }^{[11]}$ They may also have a number of complications either in childhood or during adulthood, including musculoskeletal, malnutrition, lung disease, breathing problem, and mental health problems. ${ }^{[12]}$

The diagnosis of CP is not always clear but should be suspected when a child has significant abnormalities in motor function. ${ }^{[9]}$ A clear diagnosis is very important for caregivers with CCP to help them understand their children's problems, plan for the future, and improve their health outcomes. ${ }^{[12]}$ Magnetic Resonance Imaging (MRI) scan or Computerized Tomography (CT) scan are often used in the diagnosis of CP. The findings of these scans may help to identify brain injuries or problems in brain development. ${ }^{[12]}$

According to Khattab (2014), early treatment of CP and continuous involvement of caregivers in the children's treatment sessions and ongoing therapy at home may have positive outcomes regardless of the severity of the children's conditions. ${ }^{[13]}$ The common treatments of CP include therapies, medications, and surgery with therapy often being the first choice of treatment. ${ }^{[9]}$ Medications and surgery may be used as necessary, but these treatments often require caregivers' involvement, which create challenges for them that need to be addressed.

\section{METHOD}

A search of the literature was conducted in the following electronic databases: Cumulative Index to Nursing and Allied Health Literature (CINAHL), Medline, and ERIC. The search keywords or terms were: child*, children with cerebral palsy, cerebral palsy, parent's challenges, primary caregivers, caregivers need, support group*, quality of life, quality of care, and cope. The Boolean operators AND and OR were used to narrow or broaden the search. The limiters were: i) written in English, ii) published between 2008 and 2018, and iii) primary and peer reviewed studies. The inclusion criteria for retrieving relevant articles were the following: articles discussing caregivers' needs and challenges caring for $\mathrm{CCP}$; articles discussing CCP needs; articles discussing CP as disease; articles discussing interventions of support groups for caregivers with CCP; articles discussing quality of life for CCP and their caregivers; and articles studying CCP with ages from birth to 14 years old. The initial search resulted in 139 articles from CINAHL, 18 articles from Medline, and 
44 articles from ERIC for a total of 201 articles. Application of the limiters and the inclusion criteria results in 11 articles for inclusion in this literature review: five were qualitative and six quantitative studies.

\subsection{Quality appraisal of retrieved articles}

The 11 articles were critically appraised by using the Mixed Methods Appraisal Tool (MMAT) version 2018. ${ }^{[14]}$ The MMAT is defined as "a critical appraisal tool that is designed for the appraisal stage of systematic mixed studies reviews, i.e., reviews that include qualitative, quantitative and mixed methods studies" (p. 1). This tool helps to measure the methodological validity, quality, and relevance of studies to project's research questions. It includes two stages: the first stage assesses all types of studies and the second stage consists of five questions related to specific types of study. As critical appraisal is about making judgments, two reviewers should appraise each of the studies independently. ${ }^{[14]}$ After critically appraising all 11 articles all were considered to have met the MMAT requirements and, hence, were retained.

\section{Findings}

The data from the 11 articles were critically reviewed and four themes about caregivers' needs were identified. These were: informational, financial, social and psychological needs.

\subsection{Informational needs}

Information is one important need for caregivers. Caregivers feel isolated and may be afraid because of their lack of knowledge about and clear understanding of $\mathrm{CP}^{[15]}$ Their lack of knowledge about $\mathrm{CP}$ and the lack of community resources available leads caregivers to feel that society places less value on the lives of CCP and that their children are stigmatized. Their feelings of isolation may lead to depression. ${ }^{[4,16]}$ Caregivers facing many challenges about the nature of $\mathrm{CP}$ feel that their suffering is not recognized by other people around them. ${ }^{[4]}$ They require specific information about $\mathrm{CP}$ that can be provided through participation in a support group. ${ }^{[17]}$ Their informational or knowledge needs may be met by training them to promote their critical thinking and to gain the ability for problem solving. ${ }^{[17]}$ Training them through support groups increases their knowledge and their confidence, which may improve the care they provide to their children. ${ }^{[18,19]}$ Knowledge gained through discussions in support groups may help caregivers to meet the unique needs of their CCP and to make informed decisions. ${ }^{[19]}$ A significant relationship has been shown between support groups and improved caregivers' knowledge and experience when providing care to their $\mathrm{CCP}^{[17]}$ Support groups may help caregivers by offering the best way to promote safe, timely, and effective care for their CCP. ${ }^{[16,17]}$ In addition to formal knowledge, sharing experiences in support groups also enables caregivers to gain practical knowledge and skills for the day-to-day management of their CCP. ${ }^{[17,20]}$

\subsection{Financial needs}

Support with financial needs is a recurring need expressed by caregivers. The majority of financial needs identified in the literature were related to the financial burden associated with the cost of equipment, treatments, therapies, insurance, and access to community services. ${ }^{[4,5]}$ Such a financial burden places a great deal of stress on caregivers. To meet these costs, caregivers need strong financial support. Some caregivers have low income, which may increase their level of stress and negatively affect their quality of life. ${ }^{[5]}$ Caregivers fear not being able to meet the cost of improving their children's quality of life. ${ }^{[4,5,21]}$ Most of the countries around the world may provide some financial support for individuals with disabilities and their caregivers to decrease the effect of financial challenges..$^{[5,22,23]}$ This financial support may be provided through social support services from governmental agencies. $^{[15]}$

\subsection{Social needs}

Social support is very important for caregivers to be able to care for their children. ${ }^{[15]}$ Support groups are designed specifically to offer a means of social support for members and to enhance their coping skills. ${ }^{[15]}$ Caregivers of CCP at times may need assistance from other family members or friends to relieve them in the care of their children or in case they need to attend appointments in the community. ${ }^{[4,15,23]}$ Caregivers feel confused with their children's condition, such as the type of $\mathrm{CP}$ or severity of motor impairments. This may increase their level of stress and lead to decreased level of satisfaction. ${ }^{[15]}$ Some caregivers feel unable to discuss health issues of their children with others. Their occupation and level of education also have an effect on social relations with others and effective decision making. ${ }^{[15]}$ These are considered as social requirements, which are sources of stress for the caregivers as stress may lead to depression or isolation because they need to make extra efforts to meet the needs of their children. ${ }^{[5]}$ Support groups may help to reduce the isolation and stress experienced by the members, allow for both giving and receiving emotional support. ${ }^{[19]}$ Therefore, caregivers also need psychological support through participation in support groups to decrease their stress. ${ }^{[17,19]}$

\subsection{Psychological needs}

Psychological need has been identified as important for caregivers as the other needs described above. Caregivers often express having psychological needs because of their fear, 
anxiety, and discomfort of their children's disability. ${ }^{[4,5,15]}$ Caregivers need to decrease their fear or stress related to their children's diagnosis and demands, need for lifelong treatment, lack of information and education, stigmatization, children's future, and financial burdens. ${ }^{[4]}$ Psychological support will decrease and manage caregivers' level of stress by helping them to develop coping strategies. ${ }^{[4]}$ Coping strategies are the thoughts, emotions, and behaviors that are used to adjust to any changes occurring in a person's life. These strategies may be effective for some people more than others depending on their response to stressful situations. ${ }^{[27]} \mathrm{Cop}-$ ing strategies may be positive or negative. Positive strategies may include, seeking support, exercising, watching movies, going on vacation, time management, and socializing. They are linked with positive psychological outcomes, such as optimism, lower stress, acceptance, and emotional well-being On the other hand, negative coping (e.g., worrying, isolation from social relations, not exercising, and aggressive behavior) are linked with negative psychological outcomes, such as feelings of hopelessness, depression, burden, and anxiety.

When caregivers face any difficult situations during daily care, they need to have people around them because it makes the issues much easier to deal with. ${ }^{[4]}$ If they have one or two trusted friends in a support group, they can rely on these individuals to listen to them and help them as needed. ${ }^{[17]}$ Caregivers with unmet psychological needs have low levels of quality of life. However, psychological support provided to them through support groups may improve their quality of life. ${ }^{[21]}$

In sum, based on the review of the literature, caregivers' needs in the care of their CCP were informational, financial, social, and psychological needs. Meeting these needs has the potential to increase caregivers' coping skills and confidence in caring for their children.

\section{Discussion}

The aim of this paper was to identify the needs of caregivers of CCP. The literature review identified the following support needs of caregivers: informational, financial, social, and psychological needs. With respect to informational needs caregivers expressed their priorities to have good knowledge about their children's disease and how to deal with them. ${ }^{[5]}$ This was supported by King et al. (2004) who found that $91 \%$ of caregivers caring for children with chronic health conditions expressed their need for information about their children's health conditions, implications, and treatment. ${ }^{[24]}$ Caregivers may have fear of and confusion with the lack of information about $\mathrm{CP}$, educational programs available, and differing information from community members. ${ }^{[4,22,23]}$ They also express their need to know specific information about their children's transition to school because the transition process has to include a gradual shift in the responsibilities of caregivers from caring for CCP to caring for adults with $\mathrm{CP}^{[5]}$ Findings of this literature review showed that caregivers require information about community resources, current services, and effective support to prevent them from experiencing social isolation, stress, and negative physical and emotional impacts. ${ }^{[4,5,23]}$ This was consistent with findings from other sources. ${ }^{[19]}$ Such experiences may result from the lack of information provided to caregivers related to rehabilitation services, or they do not have access to support and training. ${ }^{[19]}$ This lack of information affects negatively on care provided to CCP and on the communication between caregivers and healthcare providers possibly resulting in misinformation. ${ }^{[4]}$ Caregivers can increase their information by involvement in support groups. ${ }^{[20]}$ They also need to trust the information provided through support groups. Information from support groups gives caregivers feelings of competence and well-being, which potentially meets their needs. ${ }^{[25]}$

Financial needs result from limited access to free medical services and lack of financial support from the governmental agencies. ${ }^{[4]}$ Sen and Yurtsever (2007) reported that financial burden on caregivers included children's care, treatment, equipment, and therapy. These issues are mostly experienced by caregivers who do not have sufficient financial support. ${ }^{[26]}$ These caregivers often have low incomes, which may lead to increased levels of stress and decrease in their quality of life. This may be from a lack of free community services and therapies.

Caregivers expressed their needs for social support because they have a lack of social and emotional support provided by family members especially when caregivers are not living in their home country. ${ }^{[15]}$ This leads them to feel overloaded by the responsibility of caring for their children. ${ }^{[4]}$ Work overload makes caregivers challenged between hospital appointments for their $\mathrm{CCP}$ and caring for them at home. They also feel confused about their children's condition, such as the type of CP or severity of motor impairment. ${ }^{[4]}$ Sharing their social concerns and priorities with healthcare providers may help caregivers to meet their needs from services provided and get the needed support for desired outcomes. ${ }^{[5]}$ Sometimes children's conditions make their caregivers feel isolated and unable to share their social concerns, feelings of stigmatization, and to discuss any issues related to their children's health with others. ${ }^{[4,5]}$ These issues may decrease caregivers' level of satisfaction. ${ }^{[4]}$ However, caregivers' occupation and level of education may affect the nature of social relationships with others and their level of satisfaction. ${ }^{[15]}$ Social support is one of the important coping strategies that may help caregivers who take care of CCP. ${ }^{[27]}$ 
Caregivers in this literature review expressed their needs for psychological support. They expressed their feelings of fear and anxiety from their children's CP diagnosis and treatment, invasion of privacy, dependence of their children and the uncertainty of the future, and possible complications that may lead to death. ${ }^{[4]}$ As well, they expressed their discomfort with life-long treatment of their CCP and associated stigmatization. They need psychological support to support their children during care. ${ }^{[15]}$ To meet their psychological needs, caregivers and their children need to be involved in community activities or support group programs. ${ }^{[16,28]}$ In addition to such community support programs, healthcare providers play an important role in providing psychological support for caregivers preparing them for essential milestones in their children's lives. ${ }^{[5]}$

\subsection{Strengths and limitations}

This literature review had several strengths and limitations. Using primary and peer reviewed qualitative and quantitative studies was one of its strengths. These studies provided rich data about caregivers' and CCPs' needs, as well as the benefit of support groups. Another strength of this review was using studies published between 2008 and 2018, which provided the most current information available related to the subject of discussion. However, this review also had some limitations. For one, none of the 11 retrieved studies was done in Qatar or in any of the other Gulf countries.. Another limitation was that most of these studies were done in a single setting, and the sample size in most of the studies was small, which made it difficult to generalize their findings.

\subsection{Implications and recommendations}

The findings from this literature review may provide insight into the needs of caregivers in caring for their CPP and the challenges they face. These findings will be of benefit to healthcare providers in raising their awareness of the lifelong stressors faced by caregivers and in introducing interventions to meet their needs. The findings of this review also highlight the benefits of the availability and accessibility of support groups for caregivers of CCP. Policy-makers should invest in the establishment of such support groups under a suitable umbrella such as the Child Development Center in Qatar. For successful implementation of support groups, they should be supported by trained group leaders or facilitators to ensure that discussions are focused on needs and are conducted in a supportive environment. The design and delivery of these support groups should be contextually driven, in terms of language and culture, and be such that caregiver's informational, financial, social, and psychological needs are discussed and shared among the participants. The process and impact of the support groups will need to be evaluated and tested by valid and reliable measures. Evaluation will be useful to make improvements in the design and delivery of these programs in the future.

\section{Conclusion}

The aim of this paper was to identify the needs of caregivers of children with CP. Caregivers face many challenges when providing daily care to their children. They often have high levels of stress and negative changes in their and their children's quality of life due to their children's health conditions. Caregivers have informational, financial, social, and psychological needs, which could be met through participation in support groups. Meeting their needs, caregivers' coping skills and confidence in caring for CCP will potentially improve with positive outcomes for themselves and their children.

\section{CONFlicts of InTEREST Disclosure}

The authors declare that there is no conflict of interest.

\section{REFERENCES}

[1] Wu J, Zhang J, Hong Y. Quality of life of primary caregivers of children with cerebral palsy: A comparison between mother and grandmother caregivers in anhui province of china. Child Care Health Dev. 2017; 43: 718-724. Available from: http://ezproxy.lib.ucalgary.ca/login?url=http: //search. ebscohost. com/login. aspx?direct=true\&d $\mathrm{b}=\mathrm{rzh} \& A N=124504986 \&$ site=ehost - live $\quad$ PMid:28497475 https://doi.org/10.1111/cch.12464

[2] World Health Organization. World report on disability. Malta: World Health Organization; 2011. Available from: https://apps.who.int/iris/bitstream/handle/10665/7 0670/WHO_NMH_VIP_11.01_eng.pdf ; j sessionid=00B36099 CD6C81AC13D7E6C22D6CA610? sequence $=1$
[3] Ministry of Development Planning and Statistics. Qatar - Social Statistics 2007-2016. 2017. https://www . psa.gov. qa/en/stat istics/Statistical\%20Releases/Social/GenrealSocial Statistics/QatarSocialStatistics/Qatar_Social_Stat istics_2007_2016_En.pdf

[4] Alaee N, Shahboulaghi F, Khankeh H, et al. Psychosocial challenges for parents of children with cerebral palsy: A qualitative study. J Child Fam Stud. 2015; 24: 2147-2154. Available from: http://ezproxy.lib.ucalgary.ca/login?url=http: //search.ebscohost.com/login.aspx?direct $=$ true $\& \mathrm{db}=\mathrm{rzh} \& \mathrm{AN}=109793991 \&$ site $=$ ehost - live https://doi.org/10.1007/s10826-014-0016-3

[5] Palisano RJ, Almarsi N, Chiarello LA, et al. Family needs of parents of children and youth with cerebral palsy. 
Child Care Health Dev. 2010; 36: 85-92. Available from: http://ezproxy.lib.ucalgary.ca/login?url=http: //search.ebscohost. com/login.aspx?direct=true\&d $\mathrm{b}=\mathrm{rzh} \& A N=105277597 \&$ site $=$ ehost-live $\quad$ PMid: 19961501 https://doi.org/10.1111/j.1365-2214.2009.01030.x

[6] Ketelaar M, Volman MJM, Gorter JW, et al. Stress in parents of children with cerebral palsy: What sources of stress are we talking about? Child Care Health Dev. 2008; 34: 825-829. Available from: http://ezproxy.lib.ucalgary.ca/login?url=http: //search.ebscohost.com/login. aspx?direct=true\&d $\mathrm{b}=$ rzh\&AN $=105448783 \&$ site $=$ ehost - live $\quad$ PMid: 18959579 https://doi.org/10.1111/j.1365-2214.2008.00876.x

[7] World Health Organization. Promoting the development of young children with cerebral palsy: A guide for mid-level rehabilitation workers. Geneva: World Health Organization; 1993. Available from: https://apps. who.int/iris/bitstream/handle/106 65/62696/WHO_RHB_93.1.pdf? sequence=1\&isAllowed=y

[8] Dambi JM, Jelsma J, Mlambo T, et al. An evaluation of psychometric properties of caregiver burden outcome measures used in caregivers of children with cerebral palsy: A systematic review protocol. Systematic Reviews. 2016; 5: 42. Available from http://ovidsp. ovid. com/ovidweb.cgi?T=JS\&CSC=Y\&NEW $\mathrm{S}=\mathrm{N} \& P A G E=$ full text $\& D=$ med8\&AN=26960677 $\quad$ PMid:26960677 https://doi.org/10.1186/s13643-016-0219-3

[9] Chaplin S. Assessment and management of cerebral palsy in the under-25s. PRESCRIBER. 2017; 28: 41-44. https : //doi .org/10 $.1002 / \mathrm{psb} .1573$

[10] Dambi JM, Mandizvidza C, Chiwaridzo M, et al. Does an educational workshop have an impact on caregivers' levels of knowledge about cerebral palsy? A comparative, descriptive cross-sectional survey of Zimbabwean caregivers. Malawi Medical Journal. 2016; 28: 167-173. PMid:28321280 https://doi.org/10.4314/mmj.v28i4.4

[11] Chiluba BC, Moyo G. Caring for a cerebral palsy child: A caregivers perspective at the university teaching hospital, Zambia. BMC Research Notes. 2017; 10: 1-8. PMid:29221493 https://doi.org/ 10.1186/s13104-017-3011-0

[12] Colver A, Fairhurst C, Pharoah POD. Cerebral palsy. Lancet. 2014; 383 North American Edition: 1240-1249. https://doi.org/10 $.1016 / \mathrm{S} 0140-6736(13) 61835-8$

[13] Khattab OA. Early treatment of cerebral palsy may reduce complications. 2014. Available from: https://www.gulf-times .com/story/396441/Early-treatment-of-cerebral-pal sy-may-reduce-compl\# : : text=\%E2\%80\%9CWhile $\% 20$ we $\% 2$ 0are $\% 20$ not $\% 20$ able, occur $\% 2$ beyond $\% 20$ the $\% 20$ age $\% 20$ of

[14] Hong QN, Gonzalez-Reyes A, Pluye P. Improving the usefulness of a tool for appraising the quality of qualitative, quantitative and mixed methods studies, the mixed methods appraisal tool (MMAT). J Eval Clin Pract. 2018; 24: 459-467. PMid:29464873 https: //doi.org/10.1111/jep.12884

[15] Pfeifer LI, Silva DBR, Lopes PB, et al. Social support provided to caregivers of children with cerebral palsy. Child: Care, Health \& Development. 2014; 40: 363-369. PMid:23734935 https://doi. org/10.1111/cch.12077
[16] Fung BKK, Ho SMY, Fung ASM, et al. The development of a strength-focused mutual support group for caretakers of children with cerebral palsy. East Asian Arch Psychiatry. 2011; 21: 64-72.

[17] Jackson JB, Steward SR, Roper SO, et al. Support group value and design for parents of children with severe or profound intellectual and developmental disabilities. J Autism Dev Disord. 2018; 48: 42074221. PMid:29980899 https ://doi .org/10.1007/s10803-018 $-3665-z$

[18] Kruijsen-Terpstra A, Verschuren O, Ketelaar M, et al. Parents' experiences and needs regarding physical and occupational therapy for their young children with cerebral palsy. Res Dev Disabil. 2016; 53: 314-322. PMid:26970858 https ://doi .org/10.1016/j.ri dd.2016.02.012

[19] Zuurmond M, O'Banion D, Gladstone M, et al. Evaluating the impact of a community-based parent training programme for children with cerebral palsy in ghana. PLOS ONE. 2018; 13: 1-17. PMid:30180171 https://doi.org/10.1371/journal . pone.0202096

[20] Ödman P, Richt B, Öberg B. Parents' conceptions of intensive group training. the case of cerebral palsy. Disabil Rehabil. 2009; 31: 293301. PMid:19378396 https://doi.org/10.1080/0963828080 1945709

[21] Guillamón N, Nieto R, Pousada M, et al. Quality of life and mental health among parents of children with cerebral palsy: The influence of self-efficacy and coping strategies. Journal of Clinical Nursing (John Wiley \& Sons, Inc ). 2013; 22: 1579-1590. PMid:23461414 https://doi.org/10.1111/jocn.12124

[22] Buran CF, Sawin K, Grayson P, Criss S. Family needs assessment in cerebral palsy clinic. J Spec Pediatr Nurs. 2009; 14: 86-93. PMid:19356202 https://doi.org/10.1111/j.1744-6155.20 08.00176.x

[23] Glenn S, Cunningham C, Poole H, et al. Maternal parenting stress and its correlates in families with a young child with cerebral palsy. Child Care Health Dev. 2009; 35: 71-78. PMid:18991973 https://doi.org/10.1111/j.1365-2214.2008.00891.x

[24] King S, Teplicky R, King G, et al. Family-centered service for children with cerebral palsy and their families: A review of the literature. Semin Pediatr Neurol. 2004; 11: 78-86. PMid:15132256 https://doi.org/10.1016/j.spen.2004.01.009

[25] Johns A, Gutierrez Y, Colette Nicolaou D, et al. A support group for caregivers of children with craniofacial differences. Soc Work Groups. 2018; 41: 211-226. https ://doi .org/10.1080/016095 13.2017 .1333480

[26] Sen E, Yurtsever S. Difficulties experienced by families with disabled children. J Spec Pediatr Nurs. 2007; 12: 238-252. PMid:17956372 https://doi.org/10.1111/j.1744-6155.2007.00119.x

[27] Mantri-Langeveldt A, Dada S, Boshoff K. Measures for social support in raising a child with a disability: A scoping review. Child: Care, Health and Development. 2019; 45: 159-174. PMid:30690765 https://doi.org/10.1111/cch.12646

[28] Mihaylov SI, Jarvis SN, Colver AF, et al. Identification and description of environmental factors that influence participation of children with cerebral palsy. Dev Med Child Neurol. 2004; 46: 299-304. https://doi.org/10.1111/j.1469-8749.2004.tb00489.x 